\title{
Pendidikan Kesehatan dengan Media Film "Derita Tiada Akhir" Menggugah Pengantin Remaja dalam Menggunakan Kontrasepsi Modern
}

\author{
Tatik Kusyanti ${ }^{1}$, Farid Husin², Hadyana Sukandar² \\ 1 Jurusan Kebidanan Bandung Poltekkes Kemnkes Bandung \\ Jalan Pajajaran No.56, Pasir Kaliki, Cicendo, Kota Bandung, Jawa Barat 40171 \\ 2 Universitas Padjajaran Bandung \\ Jl. Raya Bandung Sumedang Km. 21, Hegarmanah, Jatinangor, Kabupaten Sumedang, Jawa Barat 45363 \\ Email: tia_poltekesbdg@yahoo.com
}

\begin{abstract}
Abstrak
Pernikahan remaja (10-19 tahun) merupakan masalah bagi setiap negara, terutama untuk negara-negara berkembang. Berdasarkan penelitian kesehatan dasar (Riskesdas), pernikahan remaja di Indonesia adalah 41,9\% dan ini merupakan angka tertinggi dibandingkan dengan kategori usia lainnya. Jumlah pernikahan remaja di Jawa Barat adalah di urutan kedua setelah Kalimantan Tengah dan posisi tersebut di atas nasional yakni 50,2\%. Jumlah pernikahan remaja di Bandung adalah 23,9\%, sedangkan target pemerintah hanya 3,5\%. Perkawinan remaja memiliki hubungan yang kuat dengan kehamilan dan persalinan berisiko tinggi. Tujuan penelitian ini adalah untuk menganalisis penggunaan dan dampak media film tentang risiko kehamilan remaja terhadap partisipasi kontrasepsi modern dan faktor-faktor yang memengaruhi. Penelitian ini dilakukan di 7 kantor urusan agama (KUA) yang tersebar di Bandung. Penelitian ini merupakan penelitian quasi eksperimen dengan desain post-test dan desain pre-post test dengan jumlah sampel 44 yang terdiri dari 22 pasangan pengantin dan 22 pengantin remaja yang hanya mendaftarkan pernikahan mereka di 7 KUA ini. Sampel pernikahan remaja diambil dengan consecutive sampling, sedangkan pengambilan sampel untuk remaja yang menikah diambil secara simple random sampling. Analisis univariat pada distribusi frekuensi dan binomial, sedangkan analisis bivariat digunakan chi-square dan fisher exact, analisis multivariat digunakan beberapa regresi logistik. Hasil penelitian menunjukkan bahwa pendidikan kesehatan reproduksi tentang risiko kehamilan remaja melalui media film yang bisa meningkatkan dua kali partisipasi pasangan menikah remaja dalam menggunakan kontrasepsi modern, dengan menggunakan chi-square $(p=0,015), R R:$ 2,33. Berdasarkan hasil di atas, dapat disimpulkan bahwa pendidikan kesehatan reproduksi melalui media film yang dapat meningkatkan partisipasi pengantin remaja dalam menggunakan kontrasepsi modern.
\end{abstract}

Kata Kunci: pendidikan kesehatan reproduksi, partisipasi kontrasepsi modern

\section{Health Education with Film Media "Derita Tiada Akhir" Evocative Teen Bride in Using Modern Contraception}

\begin{abstract}
Abstrac
Adolescent marriage (10-19 years old) is a problem for every country, especially for developing countries. Based on the basic health research (Riskesdas), the adolescent marriage in Indonesia is 41.9\% and this is the highest number compared with other age category. The number of adolescent marriage in West Java is in the second place after the middle of Kalimantan and the position is above the national number $50.2 \%$. The number of adolescent marriage in Bandung is $23.9 \%$, whereas the government target is only $3.5 \%$. Adolescent marriage has a strong relationship with pregnancy and the high risk childbirth. This research goal was to analyze the usage and the impact of media film the risk of adolescent pregnancy on the modern contraceptive participation and those influencing factors. The research was conducted in the 7 offices of religion affairs (KUA) that spread in Bandung. This research was a quasi experiment research with post-test design and pre-post test design with total samples of 44 consisting of 22 bridal couple and 22 adolescent bridewomen that only registered their marriage in the 7 KUA's. Adolescents marriage applicant samples were taken by consecutive
\end{abstract}


sampling whereas the sampling for the adolescents that were married was taken by simple random sampling. Univariate analysis used frequency distribution and binomial, while bivariate analysis used chi-square and fisher's exact, Multivariate analysis used Multiple Regresi Logistic. The research results show that reproductive health education about the adolescent pregnancy through film media could increase twice the participation of adolescent married couples in using modern contraception, by using chi square $(p=0.015), R R: 2.33$ have the increase of reproductive health education. Based on the results, it can be concluded that reproductive health education through film media can increase the participation of adolescent married couples influenced the modern contraceptive participation.

Keywords : reproductive health education, participation modern contraceptive

Info Artikel:

Artikel dikirim pada 29 September 2016

Artikel diterima pada 22 November 2016

DOI : http://dx.doi.org/10.21927/jnki.2016.4(3).157-162

\section{PENDAHULUAN}

Pernikahan remaja (10-19 tahun) merupakan permasalahan bagi seluruh negara, terutama bagi negara berkembang. Angka pernikahan remaja di Indonesia menurut Riset Kesehatan Dasar (Riskesdas) sebesar 41,9\% dan ini merupakan angka tertinggi dibandingkan usia lainnya. Tingginya angka pernikahan remaja ini merupakan fenomena yang sangat memprihatinkan karena timbulnya berbagai dampak negatif baik terhadap kesehatan reproduksi maupun kehidupan sosialnya. Dampak tersebut di antaranya adalah terjadinya kehamilan dengan berbagai risiko yang menyertainya, peningkatan angka morbiditas dan mortalitas baik pada ibu maupun bayinya, kekerasan dari pasangan, perceraian dan putus sekolah. perceraian, harga diri rendah, depresi, gangguan emosi, penelantaran, kemiskinan (1-6).

Pentingnya edukasi bagi pengantin remaja berkaitan erat dengan penggunaan kontrasepsi modern dan menurunnya risiko disebabkan kemungkinan kejadian kehamilan berisiko dan persalinan berisiko jadi menurun, sehingga diharapkan kematian ibu akan menurun. Berkaitan dengan kesadaran pengantin remaja dalam penggunaan kontrasepsi modern, diperlukan modifikasi media yang efektif agar penyampaian materi pentingnya kontrasepsi modern dan penundaan kehamilan pada usia remaja disebabkan kehamilan masa ini berisiko tinggi terhadap kejadian kematian $(7,8)$.

Berbagai teori menyebutkan bahwa pendidikan kesehatan yang dilakukan dengan menyajikan gambaran latar belakang yang serupa dengan sasaran/remaja tersebut dapat membuat remaja lebih tertarik. Stimulus yang diberikan dengan gambaran latar belakang/pengalaman yang sama dapat membantu sasaran merasa mengalaminya dan lebih menggugah. Semakin mirip latar belakang sosial budaya, semakin efektif komunikasi yang terjadi untuk menimbulkan perubahan perilaku. Pengalaman pribadi sangat memengaruhi penghayatan individu terhadap suatu objek, tanggapan sebagai salah satu dasar pembentukan sikap. Pengalaman pribadi meninggalkan kesan yang kuat, terutama pengalaman pribadi yang melibatkan faktor emosional dapat menjadi pemicu pembentukan sikap $(9,10)$.

Dengan adanya pendidikan kesehatan dengan multimedia yakni film yang dibuat oleh peneliti ini diharapkan penyerapan materi oleh pengantin remaja dan pemahaman serta keyakinan pengantin remaja untuk menunda kehamilan di usia remaja dengan menggunakan kontrasepsi modern lebih matang dan yakin akan menentukan keputusannya dalam menggunakan kontrasepsi modern (11).

Berdasarkan teori di atas, maka diperlukan sebuah media pendidikan kesehatan dalam bentuk audiovisual dengan menampilkan sebuah kisah yang mirip dengan pengalaman hidup remaja agar mampu mengambil keputusan yang tepat dalam menunda kehamilannya. Media pendidikan kesehatan yang sesuai dengan hal ini adalah media film tentang risiko kehamilan remaja.

Tujuan penelitian untuk mengetahui apakah ada hubungan antara pendidikan kesehatan dengan media film yang disertai ilustrasi menarik dan tampilan pesan yang kuat serta terdapat kedekatan isi pesan dengan para pengantin remaja yang akan menikah di KUA dengan penggunaan alat kontrasepsi modern setelah menikah. 


\section{BAHAN DAN METODE}

Penelitian ini bersifat analitik yang menggunakan metode gabungan ciri prospektif dan retrospektif atau yang dinamakan ambispektif analitik dengan metode kasus kontrol (case control). Populasi dalam penelitian ini adalah seluruh calon pengantin remaja dan pengantin remaja telah menikah 2 sampai dengan 4 bulan terakhir yang bertempat tinggal di wilayah kerja KUA Kota Bandung dengan sampel 22 pasang kelompok perlakuan dan 22 pasang kelompok kontrol. Pada penelitian ini pengambilan sampel pada calon pengantin remaja dilakukan dengan cara consecutive sampling yakni dengan mengambil sampel berdasarkan urutan kedatangan responden, sedangkan pengambilan sampel pada kelompok remaja yang telah menikah dilakukan secara simple random sampling yakni dengan cara diundi. Pengumpulan data dilaksanakan pada bulan Maret-April 2014. Setelah dilakukan uji reliabilitas dengan menggunakan koefisien reliabilitas Cronbach Alpha didapatkan hasil bahwa pada pertanyaan pengetahuan nilai $r$ hitung sebesar $0,636(>0,6)$ dan nilai $r$ hitung pada pertanyaan dukungan adalah 0,781 $(>0,6)$. Dengan demikian dapat disimpulkan bahwa pertanyaan pada pengetahuan dan dukungan adalah reliabel. Jenis data yang dipergunakan adalah data primer dengan instrumen pengumpulan data menggunakan kuesioner. Data yang sudah terkumpul dilakukan uji analisis univariat, bivariat, multivariat (12).

\section{HASIL DAN BAHASAN}

\section{Karakteristik Subjek Penelitian}

Berdasarkan hasil pengambilan data karakteristik didapatkan hasil sebagai berikut bahwa dari segi karakteristik didapatkan bahwa sebagian besar responden pada kelompok perlakuan dan kelompok kontrol berpendidikan terakhir SMP, lebih dari 50\% mempunyai status ekonomi <UMR, sebagian besar berstatus gadis sebelum menikah dan sebagian besar belum ingin langsung mempunyai anak.

Berdasarkan pada Tabel 1 yang menyajikan data karateristik pendidikan, status ekonomi, status saat menikah, keinginan segera mempunyai anak, hasil statistik menyatakan bahwa berdasarkan kategori pendidikan, paling banyak responden berpendidikan SMP yaitu 13 orang $(59,09 \%)$, sedangkan berdasarkan kategori UMR sebagian besar responden mempunyai penghasilan keluarga
Tabel 1. Distribusi Frekuensi Karakteristik Responden

\begin{tabular}{lcccc}
\hline \multirow{2}{*}{ Karakteristik } & \multicolumn{2}{c}{ Perlakuan } & \multicolumn{2}{c}{ Kontrol } \\
\cline { 2 - 5 } & $\mathbf{n}$ & $\%$ & $\mathbf{n}$ & $\%$ \\
\hline Pendidikan & 6 & 27,27 & 4 & 18,18 \\
$\quad$ SMA & 13 & 59,09 & 17 & 77,27 \\
SMP & 3 & 13,64 & 1 & 4,55 \\
$\quad$ SD & & & & \\
Status Ekonomi & 6 & 27,27 & 6 & 27,27 \\
$\quad$ >UMR & 16 & 72,73 & 16 & 72,73 \\
$\quad$ UMR & & & & \\
Status Saat Menikah & & 100 & 21 & 95,45 \\
$\quad$ Gadis & 0 & 0 & 1 & 4,55 \\
$\quad$ Janda & & & & \\
Keinginan Segera & & & & \\
Mempunyai Anak & 11 & 50 & 8 & 36,36 \\
$\quad$ Ya & 11 & 50 & 14 & 63,64 \\
$\quad$ Tidak & 22 & 100 & 22 & 100 \\
Total & & & & \\
\hline
\end{tabular}

Sumber: Data Primer Tahun 2013

dibawah UMR yaitu 16 orang (72,73\%). Berdasarkan kategori status saat menikah didapatkan data bahwa semua responden berstatus gadis, sedangkan berdasarkan keinginan memiliki anak sebanyak 11 orang $(50 \%)$ ingin memiliki anak.

Tabel 2. Hubungan Karakteristik Responden antara Kelompok Perlakuan dan Kelompok Kontrol

\begin{tabular}{|c|c|c|c|c|c|}
\hline \multirow{3}{*}{ Karakteristik } & \multicolumn{4}{|c|}{ Kelompok } & \multirow{3}{*}{ p-value } \\
\hline & \multicolumn{2}{|c|}{ Perlakuan } & \multicolumn{2}{|c|}{ Kontrol } & \\
\hline & $n$ & $\%$ & $\mathbf{n}$ & $\%$ & \\
\hline \multicolumn{6}{|l|}{ Pendidikan } \\
\hline SMA & 6 & 27,27 & 4 & 18,18 & \multirow{3}{*}{0,634} \\
\hline SMP & 13 & 59,09 & 17 & 77,27 & \\
\hline SD & 3 & 13,64 & 1 & 4,55 & \\
\hline \multicolumn{6}{|l|}{ Status Ekonomi } \\
\hline$>$ UMR & 6 & 27,27 & 6 & 27,27 & \multirow{2}{*}{1,00} \\
\hline$\leqq \mathrm{UMR}$ & 16 & 72,73 & 16 & 72,73 & \\
\hline \multirow{2}{*}{\multicolumn{6}{|c|}{$\begin{array}{l}\text { Status Saat } \\
\text { Menikah }\end{array}$}} \\
\hline & & & & & \\
\hline Gadis & 22 & 100 & 21 & 95,45 & \multirow{2}{*}{0,312} \\
\hline Janda & 0 & 0 & 1 & 4,55 & \\
\hline \multirow{2}{*}{\multicolumn{6}{|c|}{$\begin{array}{l}\text { Keinginan Segera } \\
\text { Mempunyai Anak }\end{array}$}} \\
\hline & & & & & \\
\hline $\mathrm{Ya}$ & 11 & 50 & 8 & 36,36 & \multirow{3}{*}{0,361} \\
\hline Tidak & 11 & 50 & 14 & 63,64 & \\
\hline Total & 22 & 100 & 22 & 100 & \\
\hline
\end{tabular}

Sumber: Data Primer Tahun 2013

Berdasarkan Tabel 2 diperoleh bahwa dari keseluruhan data tidak terdapat perbedaan yang bermakna $(p>0,05)$ antara karakteristik responden sehingga layak dibandingkan. 
Dalam tabel tersebut didapatkan data bahwa pada kelompok perlakuan sejumlah 6 responden dengan pendidikan terakhir SMA dan pada kelompok kontrol sebanyak 4 responden berpendidikan terakhir SMA. Untuk responden pada kelompok perlakuan dengan pendidikan terakhir SMP sebanyak 13 responden sedangkan kelompok kontrol sebanyak 17 responden, sedangkan yang berpendidikan SD pada kelompok perlakuan sebanyak 3 responden dan 1 responden pada kelompok kontrol. Dilihat dari jumlah tersebut tidak terpaut jauh perbedaannya dan setelah diuji memang signifikan dengan hasil tidak terdapat perbedaan yang bermakna antara kedua kelompok yang dibandingkan. Oleh karena itu pada penelitian ini kedua kelompok tersebut layak dibandingkan.

Seperti yang dikutip dalam buku Ross, S.M dengan judul Experimental Research Methods dan Campbe/ S \& Stanley JC dalam buku yang berjudul Experimental and Quasi-Experimental Designs For Research bahwa untuk mengetahui pengaruh dari perlakuan yang dilakukan pada penelitian experimental, maka kedua kelompok harus diuji homogenitasnya $(13,14)$.

Tabel 3. Perbandingan Keikutsertaan Kontrasepsi Modern antara Kelompok Perlakuan dan Kelompok Kontrol

\begin{tabular}{|c|c|c|c|c|c|c|c|}
\hline \multirow{3}{*}{ Kelompok } & \multicolumn{4}{|c|}{$\begin{array}{c}\text { Keikutsertaan } \\
\text { Kontrasepsi Modern }\end{array}$} & \multirow{2}{*}{\multicolumn{2}{|c|}{ Total }} & \multirow{3}{*}{$p$-value } \\
\hline & \multicolumn{2}{|c|}{$\mathrm{Ya}$} & \multicolumn{2}{|c|}{ Tidak } & & & \\
\hline & $n$ & $\%$ & $\mathbf{n}$ & $\%$ & $n$ & $\%$ & \\
\hline Perlakuan & 16 & 72,7 & 6 & 27,3 & 22 & 100 & 0,015 \\
\hline Kontrol & 8 & 36,4 & 14 & 63,6 & 22 & 100 & \\
\hline
\end{tabular}

Sumber: Data Primer Tahun 2013

Berdasarkan pada Tabel 3 dapat diketahui bahwa keikutsertaan kontrasepsi modern, subjek penelitian yang mendapat perlakuan jumlahnya 2 kali lipat dari subjek penelitian yang tidak mendapat perlakuan (8 responden). Hubungan antara penggunaan kontrasepsi modern kelompok calon pengantin remaja dan kelompok pengantin remaja dapat diketahui dengan menggunakan analisis chi-square. Berdasarkan hasil perhitungan statistik tersebut diperoleh nilai $\chi^{2}$ hitung sebesar 5,867 dengan nilai $p$ sebesar 0,015 .

Dari hasil tersebut maka dapat dikatakan bahwa terdapat hubungan yang bermakna dalam penggunaan kontrasepsi antara kelompok calon pengantin remaja yang mendapatkan pendidikan kesehatan reproduksi menggunakan film dengan kelompok pengantin remaja yang tidak mendapatkan pendidikan kesehatan reproduksi dengan menggunakan film. Film yang dibuat dengan konsep materi didalamnya disesuaikan dengan sosial budaya setempat dan kondisi yang disesuaikan dengan keadaan di lapangan dari segi sosial, budaya, ekonomi, strata pendidikan serta isi skenario yang sesuai dengan masalah kesehatan yang dapat terjadi pada kelompok pengantin remaja jika terjadi kehamilan di usianya berupa beberapa komplikasi-komplikasi ibu hamil dengan usia remaja diharapkan dengan isi cerita yang sesuai dengan kondisi nyata di lapangan dapat menggugah pengantin remaja tersebut untuk menunda kehamilannya sehingga terhindar dari berbagai komplikasi kehamilan di usia remaja.

Hal ini sesuai dengan teori yang dikemukakan oleh Hoffmann D Adele salah satu faktor yang memengaruhi penggunaan kontrasepsi adalah pengetahuan (15). Pendidikan kesehatan meningkatkan pengetahuan dan pengetahuan meningkatkan perilaku seseorang yang lebih positif sesuai materi dari pendidikan kesehatan tersebut. Pendidikan kesehatan yang diberikan dengan media yang menggunakan ilustrasi yang menarik dan tampilan pesan yang kuat serta terdapat kedekatan isi pesan dengan target/sasaran lebih mudah memengaruhi perilaku sasaran. Penggunaan media audiovisual dalam penelitian ini adalah dengan media film sehingga diharapkan dapat meningkatkan pengetahuan, meningkatkan penyerapan isi pesan yang disampaikan, meningkatkan ketertarikan terhadap isi materi, penerapan isi dari pesan yang disampaikan serta perubahan perilaku. Perubahan perilaku yang ditunjang oleh teori piramida yang merupakan hasil dari penelitian National Training Laboratories, Bethel, Maine dimana dalam teori tersebut mengatakan bahwa tingkat retensi/ bertahannya ingatan akan suatu ilmu dilihat dari cara belajarnya seseorang adalah sebagai berikut: lecture (dari mendengarkan orang bicara), reading (dari membaca) 10\% audiovisual (dapat dinikmati oleh mata dan telinga) 20\% demonstration (dengan praktek) $30 \%$ discussion (dengan diskusi) 50\% practice doing (dipraktekkan kekehidupan nyata) $75 \%$ teach others (mengajarkan ilmu tersebut pada orang lain) $90 \%$. Dilihat dalam teori tersebut bahwa ternyata ilmu/pengetahuan akan lebih diingat $(15,16)$.

$\mathrm{Hal}$ ini sesuai dengan hasil penelitian yang dilakukan oleh Rahmawati ira, dkk di Kalimantan Barat bahwa terdapat pengaruh penyuluhan dengan media 
audio visual terhadap peningkatan pengetahuan, sikap dan perilaku. Menurut Skinner, seperti yang dikutip oleh Notoatmodjo merumuskan bahwa perilaku merupakan respon atau reaksi seseorang terhadap stimullus (rangsangan dari luar). Oleh karena itu terjadi melalui proses adanya stimulus terhadap organisme. Stimulus bagi pengantin remaja ini dimaksudkan untuk meningkatkan pengetahuan yang diberikan melalui pendidikan kesehatan reproduksi yang disampaikan dengan menggunakan media film (17-19).

Berdasarkan jurnal berjudul Using Digital Multimedia to Improve Parents' and Children's Understanding of Clinical Trials didapatkan bahwa dari penelitian yang dilakukan di Cina penggunaan informasi digital menghasilkan peningkatan yang signifikan dalam pemahaman dibandingkan dengan format kertas tradisional (20). Hal ini menunjukkan bahwa pendekatan ini mungkin cara yang lebih baik secara aktif. Penggunaan kecanggihan teknologi dan sistem informasi yang semakin maju sangat diperlukan bermanfaat dan bersinergi dengan tujuan peningkatan bidang kesehatan terutama dalam hal ini adalah peningkatan kesehatan wanita (21).

\section{SIMPULAN DAN SARAN}

Pendidikan kesehatan reproduksi tentang risiko kehamilan remaja dengan media film dapat meningkatkan keikutsertaan kontrasepsi modern pada pengantin remaja. Adanya media yang lebih canggih, ilustrasi menarik dan sesuai dengan pengalaman hidup subjek yang melihatnya serta mengandung latar belakang sosial budaya yang mirip dapat membuat subjek/seseorang lebih trenyuh dan mengikuti pesan yang terdapat dalam media tersebut.

Media pendidikan yang berupa film dimana didalamnya terdapat skenario yang berisi materi sesuai dengan sosial budaya dan kenyataan hidup serta sosial budaya dimasyarakat tersebut sesuai dengan tujuan pendidikan kesehatan yang ingin dicapai. Berdasarkan beberapa referensi ditekankan bahwa makin canggih suatu teknologi dalam penyampaian informasi maka semakin baik penyerapan informasi oleh responden/subjek yang dituju. Selain itu kisah yang ditampilkan dalam skenario yang sesuai kenyataan hidup masyarakat pada umumnya membuat responden/subjek semakin menghayati isi skenario tersebut sebagai bahan informasi dalam kemasan sebuah media film.
Media film ini juga diharapkan dapat digunakan di seluruh KUA dan agar pelaksanaan pendidikan kesehatan reproduksi dengan menggunakan media film ini dapat lebih efektif lagi sehingga manfaatnya dapat dirasakan oleh calon pengantin yang lebih banyak lagi. Selain itu, pendidikan kesehatan reproduksi dengan menggunakan film ini juga dapat digunakan oleh BKKBN dalam program MOPEN (mobil penyuluhan) dan oleh KEMENAG dalam program P3N kepada masyarakat luas.

\section{RUJUKAN}

1. Herbal Indonesia. Bahaya Kehamilan saat remaja [Internet]. 2011. Available from: http://massaidi. blogspot.co.id/2011/10/bahaya-kehamilan-saatremaja.html.

2. Agung GN. Pengaruh Kehamilan di Usia Muda terhadap Kelahiran Premature. Bul Penelit RSUD Dr Soetomo. 2010;12(4):161-5.

3. Scholl TO, Decker E, Karp RJ, Greene G, De Sales M. Early adolescent pregnancy: a comparative study of pregnancy outcome in young adolescents and mature women. J Adolesc Health Care [Internet]. 1984 Jul;5(3):167-71. Available from: http://www.ncbi.nlm.nih.gov/pubmed/6735831.

4. Kumar A, Singh T, Basu S, Pandey S, Bhargava V. Outcome of teenage pregnancy. Indian J Pediatr [Internet]. 2007 Oct;74(10):927-31. Available from: http://www.ncbi.nlm.nih.gov/pubmed/17978452.

5. Al-Ramahi M, Saleh S. Outcome of adolescent pregnancy at a university hospital in Jordan. Arch Gynecol Obstet [Internet]. 2006 Jan;273(4):20710. Available from: http://www.ncbi.nlm.nih.gov/ pubmed/16205933.

6. Grady MA, Bloom KC. Pregnancy outcomes of adolescents enrolled in a CenteringPregnancy program. J Midwifery Womens Health [Internet]. 49(5):412-20. Available from: http://www.ncbi. nlm.nih.gov/pubmed/15351331.

7. Lintonen TP, Konu AI, Seedhouse D. Information technology in health promotion. Health Educ Res [Internet]. 2008 Jun 1;23(3):560-6. Available from: https://academic.oup.com/her/article-lookup/ doi/10.1093/her/cym001.

8. Sharif I, Wills TA, Sargent JD. Effect of visual media use on school performance: a prospective study. $J$ Adolesc Health [Internet]. 2010 Jan;46(1):52-61. Available from: http://www.ncbi.nlm.nih.gov/ pubmed/20123258. 
9. Ekasari F. Pola Komunikasi dan Informasi Kesehatan Reproduksi antara Ayah dan Remaja. Kesmas Natl Public Heal J [Internet]. 2007 Aug 1;2(1):26. Available from: http://journal.fkm.ui.ac. id/kesmas/article/view/281.

10. UNICEF. Child Protection information sheet. Geneva: UNICEF; 2009.

11. Yadav S, Choudhary D, Narayan KC, Mandal RK, Sharma A, Chauhan SS, et al. Adverse Reproductive Outcomes Associated With Teenage Pregnancy. Mcgill J Med [Internet]. 2008;11(2):141-4. Available from: https://www. ncbi.nlm.nih.gov/pmc/articles/PMC2582661/

12. Suharsimi A. Prosedur Penelitian. Jakarta: Rineka Cipta; 2010.

13. Ross SM, Morrison GR. Experimental research methods. In D. H. Jonassen. In: Handbook on educational communications and technology. 2nd ed. Mahwah, NJ: Lawrence Erlbaum Associates; 2004. p. 1021-43.

14. Campbel S, Stanley JC. Experimental and QuasiExperimental Designs For Research. Dallas: Houghton Mifflin Company; 2006.

15. Hofmann AD. Contraception in adolescence: a review. 1. Psychosocial aspects. Bul World Heal Organ Rev Anal [Internet]. 1984;62(1):151-62. Available from: https://www.ncbi.nlm.nih.gov/pmc/ articles/PMC2536285/?page $=1$.

16. Bunna AT. Desain Media Komunikasi untuk Pendidikan Konservasi berdasarkan Preeferensi
Masyarakat dan Efeknya terhadap Perubahan Pengetahuan, Sikap dan Perilaku Masyarakat di Kawasan Lindung Sungai Lesan, Berau, Kalimantan Timur [Internet]. 2010. Available from: http://repository.ipb.ac.id/bitstream/ handle/123456789/40911/2010ata.pdf?

17. MulyanaD. Pengaruh Terpaan Informasi Kesehatan di Televisi terhadap Sikap Hidup Sehat Keluarga di Kota Sumedang. J Komun Mediat. 2002;3(2):132.

18. Wilson EAH, Park DC, Curtis LM, Cameron KA, Clayman ML, Makoul G, et al. Media and memory: the efficacy of video and print materials for promoting patient education about asthma. Patient Educ Couns [Internet]. 2010 Sep;80(3):393-8. Available from: http://www.ncbi. nlm.nih.gov/pubmed/20688454.

19. Notoatmodjo 17. Promosi Kesehatan Teori dan Aplikasi, Jakarta. Jakarta: Rineka Cipta; 2006.

20. Tait AR, Voepel-Lewis T, Levine R. Using digital multimedia to improve parents' and children's understanding of clinical trials. Arch Dis Child [Internet]. 2015 Jun;100(6):589-93. Available from: http://adc.bmj.com/lookup/doi/10.1136/ archdischild-2014-308021.

21. Ira R, Toto S, Ira P. Pengaruh Penyuluhan Dengan Media Audio Visual Terhadap Peningkatan Pengetahuan, Sikap Dan Perilaku Ibu Balita, Gizi Kurang Dan Buruk Di Kabupaten Kotawaringin Barat Propinsi Kalimantan Tengah. J Gizi Klin Indones. 2007;4(2). 